\title{
Wound healing potential of palm oil tocotrienols rich fraction
}

\author{
${ }^{1}$ Ting, T.M., ${ }^{1,2, * \text { King, J.H., }}{ }^{3}$ Ho, K.L. and ${ }^{4}$ Lau, H.L.N. \\ ${ }^{I}$ Department of Crop Science, Faculty of Agricultural Science and Forestry, Department of Crop Science, \\ Universiti Putra Malaysia, Jalan Nyabau, Peti Surat 396, 97008 Bintulu, Sarawak, Malaysia \\ ${ }^{2}$ Institut Ekosains Borneo, Universiti Putra Malaysia, Jalan Nyabau, Peti Surat 396, 97008 Bintulu, \\ Sarawak, Malaysia \\ ${ }^{3}$ Department of Pathology, Faculty of Medicine and Health Sciences, Universiti Putra Malaysia, 43400 \\ UPM Serdang, Selangor, Malaysia \\ ${ }^{4}$ Energy and Environment Unit, Engineering and Processing Division, Malaysia Palm Oil Board, No.6 \\ Persiaran Institusi, Bandar Baru Bangi, 43000 Kajang, Selangor, Malaysia
}

\section{Article history:}

Received: 1 February 2021

Received in revised form: 3

March 2021

Accepted: 13 April 2021

Available Online: 31 August

2021

\section{Keywords:}

Tocotrienols,

TRF,

Diabetes,

Wound recovery,

Platelet-derived growth

factors (PDGF),

Malondialdehyde (MDA)

DOI:

https://doi.org/10.26656/fr.2017.5(4).058

\begin{abstract}
Diabetic patients often experience problems with their immune system activation and result in delayed wound healing. Slow and incomplete wound healing increases the risk of complications caused by infected wounds. Metformin has been used as a standard drug for diabetes treatment and it accelerates wound healing. However, intake of metformin may cause gastrointestinal symptoms including diarrhoea, nausea and abdominal discomfort. Therefore, a safe alternative to metforminis is required. While many research programs focus on alpha-tocopherol, in this paper the potency of tocotrienols in wound and diabetes management was investigated. Tocotrienol rich fraction (TRF) was tested for its ability to stabilize blood glucose, reduce lipid peroxidation, promote platelet-derived growth factorBB and wound closure. In this study, the rodent model was used to investigate the effects of TRP in wound healing proficiency. The results showed that TRF was comparable to metformin in stabilizing blood glucose, promoting PDGF-BB in the blood during the initial wound healing stage and produced clean wound closure. Interestingly, the findings of this study showed TRF had higher potency than metformin in reducing lipid peroxidation that could delay wound healing. Hence, TRF could be a good alternative to metformin in wound and diabetes management.
\end{abstract}

\section{Introduction}

Wound healing is a series of well-orchestrated integrations and complex biological events. It requires four overlapping phases, which includes coagulation of white blood cells, inflammation, migration-proliferation of cells and tissue remodelling to complete the healing process (Tottoli et al., 2020). The ideal wound healing is rapid and complete without infection and sepsis. In diabetic patients, the risk of incomplete or uncoordinated wound healing is high (Patel et al., 2019). More recent evidence shows that diabetic patients are likely to experience disruption in haemostasis (Nurden et al., 2008; Liu et al., 2017), causing prolonged inflammation response (Schürmann et al., 2014), changes in growth factors and chemokines (Ochoa et al., 2007), alteration in proliferation, granulation, angiogenesis (Altavilla et al., 2001; Guo et al., 2020; Okonkwo et al., 2020) microcirculation (Lioupis, 2005) employment of macrophages, neutrophils and vasoconstriction (Goren et al., 2009; Mirza et al., 2009; Lin et al., 2018) and oxidative stress (Johansen et al., 2005; Xu et al., 2020). These are among the factors delaying and impairing wound healing among diabetic patients and increase the potential of microbial infection with the chronic wound (Dong et al., 2020; Xu et al., 2020).

Metformin has been used as a standard drug for diabetes treatment. It was observed that treatment with metformin accelerated wound healing through modulation of wound repair mechanism (Inouye et al., 2014; Yu et al., 2016; Han et al., 2017; Qing et al., 2019). However, intake of metformin may cause gastrointestinal symptoms including diarrhoea, nausea and abdominal discomfort, anorexia (Bailey and Turner, 1996). Not common but a high mortality rate of lactic 
acidosis or metformin-associated lactic acidosis (MALA) when an overdose of metformin is taken among patients with renal impairment (DeFronzo et al., 2016; Blumenberg et al., 2020). Metformin is also known to be a potential genotoxin (Amador et al., 2012), embryotoxin (Li et al., 2015), thus it should be avoided as a treatment for the pregnant women. Therefore, a safe alternative is required where Tocotrienols Tich Fraction (TRF) acts as a natural phytonutrient that can be extracted from crude palm oil. Tocotrienols have been gaining attention in the last two decades and are regarded as super vitamin $\mathrm{E}$ that promotes cardiovascular health, anti-cancer, immune modulation, neuro-protection, aid for cognitive function, skin protection and other clinical effects like antioxidant, anti-inflammatory properties (Meganathan and $\mathrm{Fu}, 2016)$.

In this study, TRF is proposed to have the potential in promoting wound healing among diabetic patients. Based on past research, TRF could improve body glucose utilization and insulin sensitivity (Fang et al., 2010), effectively decrease blood glucose and glycated haemoglobin (Wan Nazaimoon and Khalid, 2002), improve dyslipidaemia while maintaining vessel wall integrity (Budin et al., 2009), reverse neuropathic pain (Kuhad and Chopra, 2009), prevent cognitive deficits (Kuhad et al., 2009) in diabetic animals, improve the glycaemic status and renal function (Siddiqui et al., 2010) and prevent hyperglycaemia induced skeletal muscle atrophy associated with diabetes (Lee and Lim, 2018).

A few earlier studies showed the potential of TRF in diabetic wound healing through elevating antioxidants enzymes (Musalmah et al., 2005) improved glycaemia status and prevent DNA damage (Matough et al., 2014), promote early regeneration of both epidermal and dermal components (Elsy et al., 2017) and increase expression of genes (Xu et al., 2017). However, it is still lack of investigation on the role of TRF in the modulation of the growth factors in wound healing.

In this paper, the potency of TRF in diabetic wound treatment is compared to the standard first-line drugmetformin using rat model. The antibacterial property in TRF was tested on infections in wounds and found that it increases the time of healing and reduce the quality of the wound and causes scarring. We also evaluated the potential of TRF in modulating wound contraction, regulation of PDGF-BB growth factor, managing oxidative stress by detecting its by-product malondialdehyde (MDA), as well as blood glucose control and bodyweight of the diabetic animal model.

\section{Materials and methods}

\subsection{Anti-microbial test}

The antibacterial property of the oil palm tocotrienols rich fraction was assessed based on the diskdiffusion method (Hudzicki, 2009; Chand, 2020). Several Gram-positive bacteria such as Staphylococcus aureus, Listeria innocua and Gram-negative Escherichia coli, Pseudomonas aeruginosa and Salmonella enterica serovar Typhi were included in the test. The bacterial stock cultures were obtained from the Faculty of Agricultural Science and Forestry, Universiti Putra Malaysia Campus Bintulu. Bacteria cultures were first spread on an agar plates and labelled accordingly. Then, $6 \mathrm{~mm}$ paper discs (Whatman no.1) with different concentrations of TRF were aseptically transferred onto the agar plate and incubated at $37^{\circ} \mathrm{C}$ for $24 \mathrm{hrs}$. A positive control (standard drug) and negative control (diluent- absolute ethanol) were included in the test. The diameter of the inhibition zone was measured to describe the antimicrobial potency of TRF.

\subsection{Wound healing test on diabetics rats}

The wound healing test was performed on diabetic rats after obtaining the approval of Institutional Animal Care and Use Committees, University Putra Malaysia (UPM/IACUC/AUP-R048/2019). Male Sprague Dawley (SD) rats of 300-400 g, supplied by the UPM Animal Resource Unit, Faculty Veterinary Medicine were used in this study. The rats were acclimatized for 14 days, kept in an open cage system with standard food (Altromin) and reverse osmosis (RO) water ad libitum and $12 \mathrm{hrs}$ light cycles at temperature-regulated conditions at Comparative Medicine and Technology Unit (COMeT), UPM.

For diabetic induction, after $8 \mathrm{hrs}$ of fasting, $65 \mathrm{mg}$ $\mathrm{kg}^{-1}$ of streptozotoxin (STZ) (Sigma, St Louis, MO, USA) in $50 \mathrm{mM}$ Sodium Citrate Buffer (Merck, Darmstadt, Germany), pH 4.5 was injected intraperitonial (i.p.) using a modified method (Furman, 2015). The rats had access to $10 \%$ sucrose (Merck, 8515) water on the day after induction and resumed RO water on the subsequent day. Feed was made available ad libitum all time during the experiment.

All SD rats proceeded for a blood glucose test after 8 hrs of fasting on the $4^{\text {th }}$ day. Blood glucose level was measured using Glucometer (Accu-Chek Performa Blood Glucose Meter). Blood pricked at the tail end using a sterilized lancet. Eight rats with blood glucose levels more than $>8.0 \mathrm{mmol} / \mathrm{L}$ were selected and randomly assigned to 2 treatment groups. 


\subsection{Wound creation}

On the same day after the blood glucose check, the diabetic rats were anaesthetized by ketamine $(50 \mathrm{mg} / \mathrm{kg})$ and xylazine $(5 \mathrm{mg} / \mathrm{kg})$ i.p and proceeded for wound induction procedures, as per modified method (Moreira et al., 2015). The dorsal fur was shaved and sterilized and two $6 \mathrm{~mm}$ full-thickness excisions were made using sterile $6 \mathrm{~mm}$ punch biopsies. The rats were separated into individual open cage systems after wound induction.

\subsection{Tocotrienols rich fraction and metformin treatment via oral gavage}

Metformin (Merck, Dramstadt, Germany) was fed to the diabetic rats in Treatment 1 as the positive control. Oil palm Tocotrienols Rich Fraction (TRF) supplied by SOP Green Energy Sdn. Bhd. was administrated to the diabetic rats in Treatment 2. The TRF used were of $50 \%$ concentration strength verified by the supplier and contained less than $25 \% \alpha$ - tocopherol and more than $75 \%$ full spectrum of tocotrienols (consist of $\alpha, \beta, \gamma$ and $\delta$ - Tocotrienols). The HPLC analysis of the TRF is shown in Figure 1. Mass of $30 \mathrm{mg} \mathrm{kg}^{-1}$ metformin or $400 \mathrm{mg} / \mathrm{kg}$ of TRF were given once daily, from day 0 until day 10 . The dosages were prepared using a sterilized syringe. Rats were restrained by holding the loose skin behind the ears and feeding using a curved metal cannula (Krinke, 2000) by oral gavage.

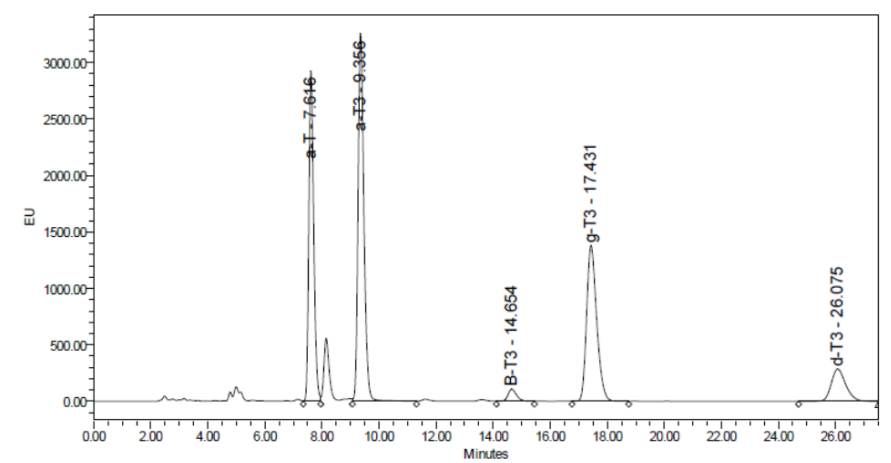

Figure 1. The HPLC chromatogram analysis of TRF supplied by SOP Green Energy

\subsection{Monitoring bodyweight and blood glucose level}

The bodyweight of rats was weighed before STZ induction at day-4 and after wound creation throughout the study period. The rat was put in a weighing bowl for bodyweight measurement using benchtop balance (AND, Fx1200 i). The blood glucose of the rat was measured on days 0, 2, 6 and 10, using test strips (Roche Accu-Chek Instant, 07819374).

\subsection{Wound contraction}

The wounded area was recorded on Day 0 immediately after wound creation and at day 2, day 6 and day 10. The areas of the wounds were measured after blood sampling. A transparent plastic sheet was pressed on the excisions sites to record the actual wound size. The area of the wound size was interpreted using the graph paper of $2 \times 2 \mathrm{~mm}$ smallest scale.

The closure was expressed as a percentage of reduced wound area over the original wound area. The area of the epidermal tongue was used to assess the rate of wound contraction during healing time (Wall et al., 2002). Wounds were considered closed if moist granulation tissue was no longer apparent and the wound appeared to be covered with epithelium (Greenhalgh et al., 1990). Wound contraction was calculated based on the following formula:

Wound contraction $(\%)=($ original wound area - current wound area $) /($ original wound area $) \times 100$

\subsection{Blood sampling}

Blood samplings were done on each rat from their tail vein using a sterile needle and sterile syringe (Terumo) on day 0 and day 2 with needle $25 \mathrm{G} \times 1$ " and using Cardiac puncture method on day 10 (Donovan and Brown, 2006). The experimental animals were anaesthetized i.p. by ketamine $(50 \mathrm{mg} / \mathrm{kg})$ and xylazine $(5 \mathrm{mg} / \mathrm{kg})$ while maintaining the temperature around $24^{\circ}$ $\mathrm{C}$ to $27^{\circ} \mathrm{C}$. If the vein was not visible, the tail was dipped into warm water $\left(40^{\circ} \mathrm{C}\right)$. The tail was not rubbed from the base to the tip as it will result in leukocytosis. About 0.6- $1.0 \mathrm{~mL}$ per withdrawal of blood sample was collected according to IACUC guideline. Samplings were limited to Day 0, Day 2 and Day 10 throughout the 10 days observation to reduce stress to the experimental rats. This limitation inhibited the observation trend of platelet-derived growth factor-BB daily release pattern throughout the 10 days of observation, however, it was necessary because stress could affect the outcome of the study. Blood glucose levels were tested immediately and the balance of blood was kept in the centrifugal vial in a cooler box for the blood serum process on the same day.

\subsection{Blood serum preparation; platelet-derived growth factor- $B B$ and malondialdehyde testing}

Blood serums were collected from centrifugation at $1,000 \times \mathrm{g}$ for $15 \mathrm{mins}$ at $4^{\circ} \mathrm{C}$ after allowing blood to stand at below $25^{\circ} \mathrm{C}$ for $2 \mathrm{hrs}$.

The blood serums were stored at $-80^{\circ} \mathrm{C}$ in the freezer until the testing date. The serum was used for plasmaderived growth factor-BB, Platelet-derived growth factor -BB (E-EL-R0537-Elabscience) and Malondialdehyde, MDA (E-EL-0060-Elabscience) content testing using Elisa kit- based on manufacturer's procedure (Elabscience, Texas, USA). 
Table 1. The Inhibitory zone of tocotrienols rich fraction (TRF) in the antimicrobial assay.

\begin{tabular}{ccccccc}
\hline Bacteria & Listeria innocua & Escherichia coli & $\begin{array}{c}\text { Pseudomonas } \\
\text { aeruginosa }\end{array}$ & $\begin{array}{c}\text { Staphylococcus } \\
\text { aureus }\end{array}$ & $\begin{array}{c}\text { Salmonella enterica } \\
\text { serovar Typhi }\end{array}$ & Remarks \\
\hline $0.5 \%$ Ethanol & - & $7 \mathrm{~mm}$ & $7 \mathrm{~mm}$ & $7 \mathrm{~mm}$ & - & Negative Control \\
$30 \mathrm{mg} / \mathrm{L}$ & - & $7 \mathrm{~mm}$ & $7 \mathrm{~mm}$ & $7 \mathrm{~mm}$ & Concentration 1 \\
$48 \mathrm{mg} / \mathrm{L}$ & - & $7 \mathrm{~mm}$ & $7 \mathrm{~mm}$ & $7 \mathrm{~mm}$ & - & Concentration 2 \\
$105 \mathrm{mg} / \mathrm{L}$ & - & $7 \mathrm{~mm}$ & $7 \mathrm{~mm}$ & $7 \mathrm{~mm}$ & - & Concentration 3 \\
& $29 \mathrm{~mm}$ & $38 \mathrm{~mm}$ & $35 \mathrm{~mm}$ & $40 \mathrm{~mm}$ & $30 \mathrm{~mm}$ (Meropenem & Positive Control \\
Standard Drug & $($ Meropenem 10 (Ciprofloxacin 1 & (Meropenem 10 & (Ampicillin 10 & $10 \mu \mathrm{g})$ \\
\hline
\end{tabular}

\subsection{Statistical analysis}

Statistical analyses were conducted using SAS one way ANOVA followed by Tukey's test. $P$ values below 0.05 were considered significant.

\section{Results}

\subsection{Antimicrobial assay}

From the antimicrobial test result using the disc diffusion method (Table 1), it shows that oil palm tocotrienols rich fraction (TRF) at concentration $30 \mathrm{mg} / \mathrm{L}$ to $105 \mathrm{mg} / \mathrm{L}$ had no antimicrobial activity against $S$. aureus, L. innocua, E. coli, $P$. aeruginosa and $S$. enterica ser, Typhi.

\subsection{Wound contraction}

Wound closure was monitored for 10 days (Table 2). Rats fed with either metformin or tocotrienols rich fraction performed equally, with no significant difference in the percentage of wound contraction. The rate of wound contraction progressed steadily at Day 2 with $39.2 \pm 1.4 \%$ for metformin treatment and $33.3 \pm 0 \%$ for TRF treatment, at Day 6 at $56.5 \pm 6.3 \%$ for metformin treatment and $59.3 \pm 6.4 \%$ for TRF treatment and Day 10 at $100 \pm 0 \%$ for metformin treatment and TRF. No worsening of wound condition or abnormal observation at wound area was observed in both treatment groups. The wound with $100 \%$ contracted at Day 10 was observed and the wound was covered with a layer of epithelium without moist granulation.

Table 2. Wound appearance and wound contraction percentage on Day 0, 2, 6 and 10

\begin{tabular}{|c|c|c|c|c|}
\hline \multirow{2}{*}{$\begin{array}{c}\text { Treatment/ } \\
\text { Wound }\end{array}$} & \multicolumn{4}{|c|}{ Wound Size, $\mathrm{mm}^{2}$} \\
\hline & Day 0 & Day 2 & Day 6 & Day 10 \\
\hline \multirow[t]{2}{*}{$\begin{array}{c}\text { T01- } \\
\text { Metformin }\end{array}$} & & & & 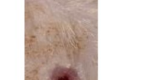 \\
\hline & $0.0 \pm 0.0 \%$ & $19.6 \pm 18.3 \%$ & $50.4 \pm 19.8 \%$ & $89.8 \pm 13.6 \%$ \\
\hline \multicolumn{5}{|l|}{ T02- TRF } \\
\hline & $0.0 \pm 0.0 \%$ & $18.3 \pm 14.7 \%$ & $47.1 \pm 18.9 \%$ & $97.0 \pm 5.5 \%$ \\
\hline
\end{tabular}

Due to the scab formation, the wound recovery rate on Day 2 and Day 6 varied slightly as shown in Table 2 . However, the wound recovery rates on Day 10 were compared after the removal of the scab. The wound closure for rats treated with TRF appeared to be more neat and complete.

\subsection{Platelet-derived growth factor-BB (PDGF-BB) Content}

The blood serum of the rats in the experiment was extracted on Day 0, Day 2 and Day 10. From the result shown in Table 3, the PDGF-BB increased on Day 2 after wound incision. Assessment based on Day 2 and Day 10 showed no significant differences between treatments for PDGF-BB content.

Table 3. Platelet derived growth factor-BB in experimental rats' blood serum on Day 0 and Day 10

\begin{tabular}{cccc}
\hline Treatment & Day 0, pg/mL & Day 2, pg/mL & Day 10, pg/mL \\
\hline T0- Metformin & $2223 \pm 113^{\mathrm{a}}$ & $2590 \pm 298^{\mathrm{a}}$ & $2430 \pm 266^{\mathrm{a}}$ \\
T1- TRF & $2095 \pm 129^{\mathrm{a}}$ & $2590 \pm 348^{\mathrm{a}}$ & $2508 \pm 372^{\mathrm{a}}$ \\
\hline
\end{tabular}

Values are presented as mean \pm SD. Values with the same superscript within the same column are not significantly different according to Tukey Test $(\mathrm{p}=0.05)$.

\subsection{Malondialdehyde (MDA) content}

Elisa assay showed both Metformin and TRF treated group showed no significant difference in their malondialdehyde (MDA) content in blood serum on Day 0 (Table 4). However, on Day 10, the MDA concentration in TRF treated group showed MDA concentration dropped, significantly lower than the metformin group $(P<0.05)$. The MDA started at $237 \mathrm{ng} /$ $\mathrm{mL}$ at Day 0 and reduced to $198 \mathrm{ng} / \mathrm{mL}$ at Day 10 for TRF treated group. While Metformin treated group, MDA tested $228 \mathrm{mg} / \mathrm{mL}$ before treatment roughly maintained at Day 10.

Table 4. Malondialdehyde (MDA) in experimental rats' blood serum on Day 0 and Day 10

\begin{tabular}{ccc}
\hline Treatment & Day $0, \mathrm{ng} / \mathrm{mL}$ & Day $10, \mathrm{ng} / \mathrm{mL}$ \\
\hline T0- Metformin & $228 \pm 25^{\mathrm{a}}$ & $222 \pm 37^{\mathrm{a}}$ \\
T1- TRF & $237 \pm 20^{\mathrm{a}}$ & $198 \pm 17^{\mathrm{b}}$ \\
\hline
\end{tabular}

Values are presented as mean \pm SD. Values with the same superscript within the same column are not significantly different according to Tukey Test $(\mathrm{p}=0.05)$. 


\subsection{Blood glucose and bodyweight}

The blood glucose and bodyweight of the experimental rats were monitored for 10 days after wound incision (Figure 2 and Figure 3). There is no significant difference between both treatments groups in their blood glucose level (Figure 2). Both experiencing reduction in blood glucose 6 days after metformin or TRF treatment. On Day 10, both TRF and metformin treated group had reached $25-26 \mathrm{mmol} / \mathrm{L}$ of blood glucose.

Bodyweights of both treatment groups decreased after STZ injection, then the decrease in weight ceased and was maintained from Day 1 onwards. The overall bodyweight among rats treated with TRF was slightly lower than that in metformin-treated rats.

\section{Blood Glucose, $\mathrm{mmol} / \mathrm{L}$}

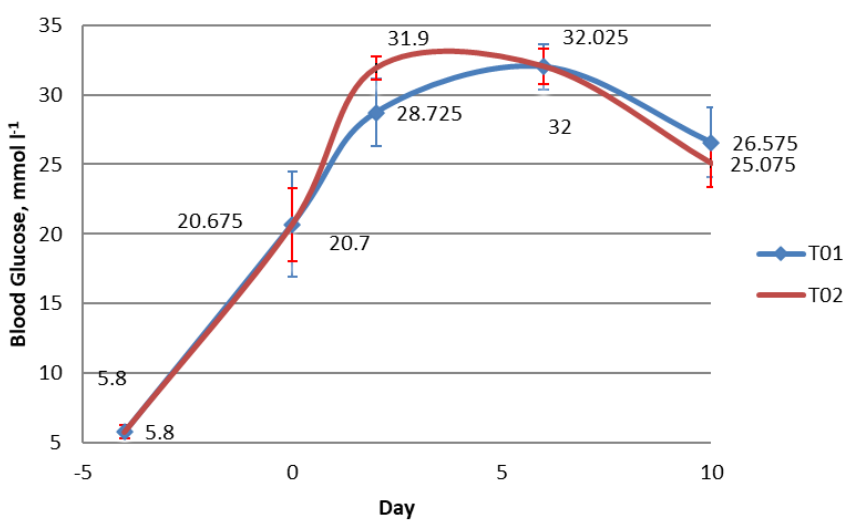

Figure 2. Mean blood glucose $(\mathrm{mmol} / \mathrm{L})$ of Metformin treated (T01) and TRF Treated group (T02) at initial, Day 0 (4 days after STZ induction), Day 2, Day 6 and Day 10.

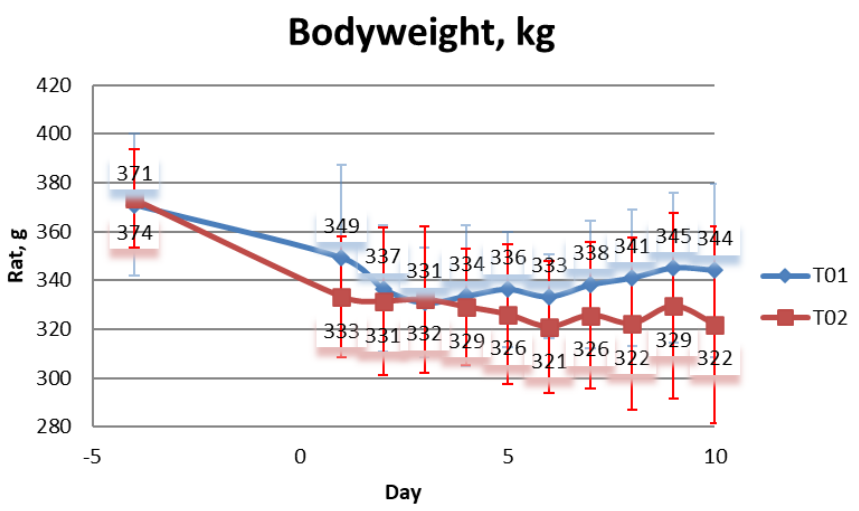

Figure 3. Mean bodyweight of Metformin treated (T01) and TRF Treated group (T02) at initial, Day 1 till Day 10

\section{Discussion}

The oil palm tocotrienols rich fraction (TRF) did not demonstrate any antimicrobial inhibitory property against $S$. aureus, L. innocua, E. coli, $P$. aeroginosa and $S$. enterica ser. Typhi at concentration $30 \mathrm{mg} / \mathrm{L}$ to 105 $\mathrm{mg} / \mathrm{L}$ h. From the research by Al-Salih et al. (2013) that vitamin $\mathrm{E}$ in concentration more than $50 \mathrm{IU} / \mathrm{mL}$ could inhibit $S$. aureus and Staphylococcus epidermidis and $P$. aeruginosa was sensitive to $200 \mathrm{IU} / \mathrm{mL}$ of vitamin $\mathrm{E}$ while $E$. coli was sensitive to $400 \mathrm{IU} / \mathrm{mL}$ (Al-Salih et al., 2013) However, based on Cheah and Gan (2000) research findings, there was no antimicrobial effect asserted by vitamin E alpha-tocopherol which is in agreement with our findings. In Al-Salih et al. (2013), the source of vitamin E used was not mentioned, thus it could result in a different outcome. Vitamin E comprises of two subfamilies that include tocopherols and tocotrienols and these compounds differ in structure and dietary source (Lee and Han, 2018), hence their potency in preventing microbial growth could be varied.

Although TRF did not display any antibacterial activity, the wound contraction progressed steadily from Day 2, 6 and 10 and showed the potential of TRF on diabetic wound healing, with no sign of infection and sepsis. During the observation period, we observed that the scab formed started on the end of Day 1 (Table 2) turned dried at day 6 and the scab started to get smaller when granulation started until a pink layer of epithelial cell appeared at the wound at Day 10. The non-delayed wound contraction rate for TRF treated wounds agreed with Musalmah et al. (2002) when compared to the wound contraction and complete epithelialization an animal model, normal and diabetic SP male rats. The TRF treated rats reached $>90 \%$ wound closure on Day 10. In the same testing, untreated diabetic rats had merely $<20 \%$ of recovery (Musalmah et al., 2002). In addition, $\mathrm{Xu}$ et al. (2017) also reported that epoxidated tocotrienols tested accelerated the wound contraction (Xu et al., 2017). The effectiveness of TRF with wound recovery without delays is also evidenced in the diabetic and non-diabetic animals models (Abu Dayyih et al., 2020).

Okizaki et al. (2015) used using STZ induced diabetic and non-diabetic animal model on wound healing and showed that the wound contraction was delayed in STZ animals during the early phase of the healing period with reduction of the recruitment of macrophages into the wound granulation tissue, that contributed to the delay in wound healing and angiogenesis compared to normal animal model (Okizaki et al., 2015). Yu et al. (2016) found that the wound contraction rate on STZ induced diabetic animal treated with metformin reached $90 \%$ at Day 10 with $6 \mathrm{~mm}$ circular wound. Their study suggested that metformin improve BM-EPC functions in STZ-induced diabetic mice, which was possibly dependent on the AMPK/ eNOS pathway (Yu et al., 2016). Our study suggested that TRF is comparable to Metformin in wound healing 
performance based on the results in Table 1, Table 2 and Table 3. The STZ induced diabetic rats fed with metformin or TRF in our study showed non-delay of wound healing.

Wound contraction is a major contributor to the healing of full-thickness open wounds compared with incisional wounds. Wounds with square edges contract more rapidly than circular wounds (Ramasastry, 2005). According to Ramasastry (2005), wound contraction started 4 to 5 days after wounding. The process involves the centripetal movement of the wound edge toward the centre of the wound. Maximal wound contraction continues for 12 to 15 days, as long as the wound remains open. Wound contraction progresses at an average of 0.6 to $0.75 \mathrm{~mm} /$ day. The tissues that have the greatest laxity demonstrate the greatest degree of wound contraction. The starting of wound contraction need platelet-derived growth factor-BB (PDGF) then only proceeds into remodelling (Ramasastry, 2005). Table 3 shows that the experimental rats fed with either metformin or TRF produced a sufficient amount of PDGF at the initial of wound healing (Day 0 to Day 2) prevented the wound to turn into a chronic non-healing wound. This agreed with the findings of Xu et al. (2017) on tocopherols and tocotrienols that induces VEGF and PDGF expression, which played important roles in cell proliferation and migration in wound healing.

PDGF-BB is the first of few growth factors delivered to the wound site by degranulated platelets as initial signals for activation of neutrophils, macrophages and fibroblasts. The response on hemostasis and inflammatory on blood serum was tested on Day 2 and noted there was a peak in PDGF-BB. The raise of PDGF -BB after injury agreed with PDGF roles in inflammatory (Steed, 1997) and initial wound recovery mechanism (Bennett et al., 2003). Based on Doxey et al. (1995), platelet-derived growth factor levels in wounded diabetic rats showed no response of PDGF until Day 20, while non-diabetic rats would have a hike in the expression of platelet-derived growth factor (PDGF) at Day 5. It is suggested that the diabetic state inhibits cellular PDGF expression in diabetes wounds (Doxey et al., 1995). Since rats in both experimental groups in this study showed an increase in PDGF levels on Day 2, therefore it indicates the potential use of both metformin and TRF in wound management in diabetic animals. Towards the end of wound closure, the PDGF-BB in blood serum would gradually drop due to the diversification of growth factors and cytokines that take place for rebuilding with new granulation and extracellular matrix as well as developing a new network of blood vessels (Stadelmann et al., 1998).
Malondialdehyde (MDA) is the product of lipid peroxidation that occurs during oxidation stress; it is generated by reactive oxygen species (ROS) (Marnett, 1999). Due to the diabetes systemic condition, there are higher MDA in the wound or ROS activities involved compared to non-diabetic wounds (Baynes, 1991; Rasik and Shukla, 2000). ROS acts as signalling molecules and defence systems while it is detrimental to cells and tissue, it stimulates the initiation of inflammatory reactions (Johansen et al., 2005; Paswan et al., 2020).

In the development of complications in diabetes, it is suggested that the oxidative stress may be amplified by a continuing cycle of metabolic stress, tissue damage and cell death, leading to increased free radical production and compromised free radical inhibitory and scavenger systems, which further exacerbate the oxidative stress (Baynes, 1991).

TRF treatment group showed a significant reduction of MDA compared to metformin-treated on Day 10 (Table 4). Musalmah et al. (2002) and Musalmah et al (2005) reported that diabetic rats would experience significantly higher plasma MDA levels compared to the normal rate, but the MDA of the diabetic rat could reduce significantly with $\alpha$-tocopherol (Musalmah et al., 2002; Musalmah et al., 2005). Our study showed that tocotrienol (TRF) could also reduce the plasma MDA, indicates its potent antioxidants and significantly reduced the lipid peroxidation levels in the wounds as measured by the reduction in MDA levels. Alpha-tocopherol and alpha-tocotrienol are both vitamin $\mathrm{E}$ constituents having the same aromatic chromanol "head" but differing in their hydrocarbon "tail": tocopherol with a saturated and tocotrienol with an unsaturated isoprenoid chain (Sen et al., 2006). This small difference in molecular structure allows tocotrienols to cover a larger surface area of the cell membrane more quickly, hence making them more effective as antioxidants. Serbinova et al. (1991) had compared the antioxidant potent of both tocotrienols and tocopherols and reported that alpha-tocotrienol is 40-60 times better than alpha-tocopherol in $\left(\mathrm{Fe}^{2+}+\right.$ ascorbate)and $\left(\mathrm{Fe}^{2+}+\mathrm{NADPH}\right)$-induced lipid peroxidation in rat liver microsomal membranes and 6.5 times more effective in protecting cytochrome P-450 against oxidative damage. The unsaturated isoprenoid side chain of the tocotrienols, which had been suggested to provide higher mobility, allowing more efficient and uniform distribution into the bilayer cell membranes (Serbinova et al., 1991). This makes tocotrienol a potential topical application for wound recovery treatment with potent anti-oxidant properties. While alpha-tocopherol research still occurs at a much greater level than tocotrienol research, the benefit of tocotrienols has to gain more attention, driven by a growing body of science. 
Lipid peroxidation generates a high level of free radicals. The free radicals impair the normal wound healing process by being injurious to a keratinocyte, endothelial cells, capillary permeability and collagen metabolism. Hence, oxidative stress induces cellular dysfunction and retards angiogenesis and the healing process. The inhibition of lipid peroxidation can restore impaired vascular endothelial growth factor expression and stimulates wound healing (Altavilla et al., 2001). Therefore, the ability of TRF in bringing down lipid peroxidation and regulating oxidative stress would increase the potent use of TRF in wound healing.

Other than wound healing, the potential of TRF in diabetes management is also of interest to this study. The blood glucose level of all rats increased from an initial $5.8 \mathrm{mmol} / \mathrm{L}$ to $21 \mathrm{mmol} / \mathrm{L}$ after 4 days of STZ induction. Administration of STZ destroyed pancreatic $b$-cells, leading to the inhibited insulin secretion, thereby increased blood glucose levels.

The blood glucose on day 2 after administration of metformin or TRF had significantly lowered the blood glucose and the metformin group had lower blood glucose than the TRF supplementary group. Metformin is the first-line therapy for type 2 diabetes mellitus to lower both basal and postprandial plasma glucose (PPG). Metformin works by inhibiting the production of hepatic glucose, reducing intestinal glucose absorption and improving glucose uptake and utilization (Gong et al., 2012).

On day 6 and day 10, the blood glucose level of both metformin and TRF treated remained slow-down, 26.5 $\mathrm{mmol}^{-1}$ for the metformin-treated group and $25.0 \mathrm{mmol}$ $\mathrm{L}^{-1}$ for TRF treated group. This indicates TRF is able to stable down the blood glucose as good as metformin. This finding provides additional support to the work of Wan Nazaimoon and Khalid (2002), that claimed TRF can stabilize the hike of the blood glucose level and prevent the further rise of glycated haemoglobin content significantly in STZ- induced diabetic rats compared to the negative control. They also postulated that TRF affects protecting the total damage of $b$-cells by STZ or glucotoxicity (Wan Nazaimoon and Khalid, 2002). Another study using STZ induced diabetes rats, with TRF oral supplement after the STZ induction, reported TRF lowers the blood glucose and improved dyslipidemia on the blood vessel wall (Budin et al., 2009).

Monitoring bodyweight is also an important component in diabetes management. For diabetic patients, insufficient insulin prevents their bodies from getting glucose from the blood into the body's cells. The loss of ability to obtain glucose as an energy source switched of energy source to the catabolism of protein and fats, which lead to a reduction in bodyweight. A previous study by Zolali et al. (2020), where metformintreated $(50$ and $100 \mathrm{mg} / \mathrm{kg}$ ) STZ induced diabetic rats showed dropped in bodyweight (Zolali et al., 2020). The bodyweight of the experimental rats in this study reduced sharply after the STZ induction to approximately 6 to 10 $\%$. After being supplemented with either metformin or TRF, the bodyweight stabilized but was not able to gain its previous weight.

\section{Conclusion}

Tocotrienols Rich Fraction (TRF) showed potential in managing diabetes and assist in wound healing. The oxidative stress experienced among the diabetic rats can be reduced with the administration of TRF where a significant reduction of MDA, the product from lipid peroxidation was noted. TRF also timely promoted the growth factor, PDGF-BB which is important for clean wound closure. Based on these findings, TRF may be considered a promising supplement in diabetic management.

\section{Acknowledgements}

The authors would like to thank Sarawak Oil Palms Berhad, Bintulu for providing tocotrienols rich fraction used in this research and to Universiti Putra Malaysia Bintulu Campus and Universiti Putra Malaysia Serdang for the use of their facilities and technical supports.

\section{References}

Abu Dayyih, W., Abu Rayyan, W. and Al-Matubsi, H.Y. (2020). Impact of sildenafil-containing ointment on wound healing in healthy and experimental diabetic rats. Acta Diabetologica, 57(11), 1351-1358. https:// doi.org/10.1007/s00592-020-01562-0

Al-Salih, D.A.A.K., Aziz, F.M., Mshimesh, B.A.R. and Jehad, M.T. (2013). Antibacterial Effects of Vitamin E: In Vitro Study. Journal of Biotechnology Research Center, 7(2), 17-23. https://www.iasj.net/ iasj/article/77182

Altavilla, D., Saitta, A., Cucinotta, D., Galeano, M., Deodato, B., Colonna, M., Torre, V., Russo, G., Sardella, A., Urna, G., Campo, G.M., Cavallari, V., Squadrito, G. and Squadrito, F. (2001). Inhibition of Lipid Peroxidation Restores Impaired Vascular Endothelial Growth Factor Expression and Stimulates Wound Healing and Angiogenesis in the Genetically Diabetic Mouse. Diabetes, 50(3), 667674. https://doi.org/10.2337/diabetes.50.3.667

Amador, R.R., Longo, J.P.F., Lacava, Z.G., Dórea, J.G. and Santos, M. de F.M.A. (2012). Metformin (dimethyl-biguanide) induced DNA damage in 
mammalian cells. Genetics and Molecular Biology, 35(1), 153-158. https://doi.org/10.1590/S141547572011005000060

Bailey, C.J. and Turner, R.C. (1996). Metformin. New England Journal of Medicine, 334(9), 574-579. https://doi.org/10.1056/NEJM199602293340906

Baynes, J.W. (1991). Role of Oxidative Stress in Development of Complications in Diabetes. Diabetes, 40(4), 405-412. https://doi.org/10.2337/ diab.40.4.405

Blumenberg, A., Benabbas, R., Sinert, R., Jeng, A. and Wiener, S.W. (2020). Do Patients Die with or from Metformin-Associated Lactic Acidosis (MALA)? Systematic Review and Meta-analysis of $\mathrm{pH}$ and Lactate as Predictors of Mortality in MALA. Journal of Medical Toxicology, 16(2), 222-229. https:// doi.org/10.1007/s13181-019-00755-6

Budin, S.B., Othman, F., Louis, S.R., Bakar, M.A., Das, S. and Mohamed, J. (2009). The effects of palm oil tocotrienol-rich fraction supplementation on biochemical parameters, oxidative stress and the vascular wall of streptozotocin-induced diabetic rats. Clinics, 64(3), 235-244. https://doi.org/10.1590/ S1807-59322009000300015

Chand, B. (2020). Antibacterial Effect of Garlic (Allium sativum) and ginger (Zingiber officinale) Against Staphylococcus aureus, Salmonella typhi, Escherichia coli and Bacillus cereus. Journal of Microbiology, Biotechnology and Food Sciences, 2 (4), 2481-2491.

Cheah, P.B. and Gan, S.P. (2000). Antioxidative/ Antimicrobial Effects of Galangal and $\alpha$-Tocopherol in Minced Beef. Journal of Food Protection, 63(3), 404-407. https://doi.org/10.4315/0362-028X63.3.404

DeFronzo, R., Fleming, G.A., Chen, K. and Bicsak, T.A. (2016). Metformin-associated lactic acidosis: Current perspectives on causes and risk. Metabolism, 65(2), 20-29. https://doi.org/10.1016/ j.metabol.2015.10.014

Dong, J., Chen, L., Zhang, Y., Jayaswal, N., Mezghani, I., Zhang, W. and Veves, A. (2020). Mast Cells in Diabetes and Diabetic Wound Healing. Advances in Therapy, 37(11), 4519-4537. https:// doi.org/10.1007/s12325-020-01499-4

Donovan, J. and Brown, P. (2006). Blood Collection. Current Protocols in Immunology, 73(1), 1.7.1-1.7.9. https://doi.org/10.1002/0471142735.im0107s73

Doxey, D.L., Ng, M.C., Dill, R.E. and Iacopino, A.M. (1995). Platelet-derived growth factor levels in wounds of diabetic rats. Life Sciences, 57(11), 11111123. https://doi.org/10.1016/0024-3205(95)02056-

\section{$\mathrm{O}$}

Elsy, B., Khan, A.A. and Maheshwari, V. (2017). Effect of vitamin $\mathrm{E}$ isoforms on the primary intention skin wound healing of diabetic rats. Our Dermatology Online/Nasza Dermatologia Online, 8(4), 369-375. https://doi.org/10.7241/ourd.20174.108

Fang, F., Kang, Z. and Wong, C. (2010). Vitamin E tocotrienols improve insulin sensitivity through activating peroxisome proliferator-activated receptors. Molecular Nutrition and Food Research, 54(3), 345-352. https://doi.org/10.1002/ mnfr.200900119

Gong, L., Goswami, S., Giacomini, K.M., Altman, R.B. and Klein, T.E. (2012). Metformin pathways: Pharmacokinetics and pharmacodynamics. Pharmacogenetics and Genomics, 22(11), 820-827. https://doi.org/10.1097/FPC.0b013e3283559b22

Goren, I., Allmann, N., Yogev, N., Schürmann, C., Linke, A., Holdener, M., Waisman, A., Pfeilschifter, J. and Frank, S. (2009). A Transgenic Mouse Model of Inducible Macrophage Depletion: Effects of Diphtheria Toxin-Driven Lysozyme M-Specific Cell Lineage Ablation on Wound Inflammatory, Angiogenic and Contractive Processes. The American Journal of Pathology, 175(1), 132-147. https://doi.org/10.2353/ajpath.2009.081002

Greenhalgh, D.G., Sprugel, K.H., Murray, M.J. and Ross, R. (1990). PDGF and FGF stimulate wound healing in the genetically diabetic mouse. The American Journal of Pathology, 136(6), 1235-1246.

Guo, W., Qiu, W., Ao, X., Li, W., He, X., Ao, L., Hu, X., Li, Z., Zhu, M., Luo, D., Xing, W. and Xu, X. (2020). Low-concentration DMSO accelerates skin wound healing by Akt/mTOR-mediated cell proliferation and migration in diabetic mice. British Journal of Pharmacology, 177(14), 3327-3341. https://doi.org/10.1111/bph.15052

Han, X., Tao, Y., Deng, Y., Yu, J., Sun, Y. and Jiang, G. (2017). Metformin accelerates wound healing in type 2 diabetic $\mathrm{db} / \mathrm{db}$ mice. Molecular Medicine Reports, 16(6), 8691-8698. https://doi.org/10.3892/ mmr.2017.7707

Hudzicki, J. (2009). Kirby-Bauer Disk Diffusion Susceptibility Test Protocol. Retrieved from American Society for Microbiology website: https:// asm.org/getattachment/2594ce26-bd44-47f6-82870657aa9185ad/Kirby-Bauer-Disk-DiffusionSusceptibility-Test-Protocol-pdf.pdf

Inouye, K.A.S., Bisch, F.C., Elsalanty, M.E., Zakhary, I., Khashaba, R.M. and Borke, J.L. (2014). Effect of Metformin on Periimplant Wound Healing in a Rat Model of Type 2 Diabetes. Implant Dentistry, 23(3), 
319-327. ID.0000000000000069

Johansen, J.S., Harris, A.K., Rychly, D.J. and Ergul, A. (2005). Oxidative stress and the use of antioxidants in diabetes: Linking basic science to clinical practice. Cardiovascular Diabetology, 4, 5. https:// doi.org/10.1186/1475-2840-4-5

Krinke, G.J. (2000). The laboratory Rat. Handbook of Experimental Animals. $1^{\text {st }}$ ed. USA: Academic Press.

Kuhad, A., Bishnoi, M., Tiwari, V. and Chopra, K. (2009). Suppression of NF- $\kappa \beta$ signaling pathway by tocotrienol can prevent diabetes associated cognitive deficits. Pharmacology Biochemistry and Behavior, 92(2), 251-259. https://doi.org/10.1016/ j.pbb.2008.12.012

Kuhad, A. and Chopra, K. (2009). Tocotrienol attenuates oxidative-nitrosative stress and inflammatory cascade in experimental model of diabetic neuropathy. Neuropharmacology, 57(4), 456-462. https://doi.org/10.1016/j.neuropharm.2009.06.013

Lee, G.Y. and Han, S.N. (2018). The Role of Vitamin E in Immunity. Nutrients, 10(11), 1614. https:// doi.org/10.3390/nu10111614

Lee, H. and Lim, Y. (2018). Tocotrienol-rich fraction supplementation reduces hyperglycemia-induced skeletal muscle damage through regulation of insulin signaling and oxidative stress in type 2 diabetic mice. The Journal of Nutritional Biochemistry, 57, 77-85. https://doi.org/10.1016/j.jnutbio.2018.03.016

Li, L., Zhang, X., Wang, L., Chai, Z., Shen, X., Zhang, Z. and Liu, C. (2015). A toxicology study to evaluate the embryotoxicity of metformin compared with the hypoglycemic drugs, the anticancer drug, the antiepileptic drug, the antibiotic and the cyclooxygenase (COX)-2 inhibitor. Journal of Diabetes, 7 (6), 839-849. https://doi.org/10.1111/17530407.12251

Lin, P.-H., Sermersheim, M., Li, H., Lee, P.H.U., Steinberg, S.M. and Ma, J. (2018). Zinc in Wound Healing Modulation. Nutrients, 10(1), 16. https:// doi.org/10.3390/nu10010016

Lioupis, C. (2005). Effects of diabetes mellitus on wound healing. Journal of Wound Care, 14(2), 8486. https://doi.org/10.12968/jowc.2005.14.2.26738

Liu, L., Lv, Q., Zhang, Q., Zhu, H., Liu, W., Deng, G., Wu, Y., Shi, C., Li, H. and Li, L. (2017). Preparation of Carboxymethyl Chitosan Microspheres and Their Application in Hemostasis. Disaster Medicine and Public Health Preparedness, 11(6), 660-667. https:// doi.org/10.1017/dmp.2015.133

Marnett, L.J. (1999). Lipid peroxidation-DNA damage by malondialdehyde. Mutation Research/
Fundamental and Molecular Mechanisms of Mutagenesis, 424(1), 83-95. https://doi.org/10.1016/ S0027-5107(99)00010-X

Matough, F.A., Budin, S.B., Hamid, Z.A., AbdulRahman, M., Al-Wahaibi, N. and Mohammed, J. (2014). Tocotrienol-Rich Fraction from Palm Oil Prevents Oxidative Damage in Diabetic Rats. Sultan Qaboos University Medical Journal, 14(1), e95e103. https://doi.org/10.12816/0003342

Meganathan, P. and Fu, J.-Y. (2016). Biological Properties of Tocotrienols: Evidence in Human Studies. International Journal of Molecular Sciences, 17(11), 1682. https://doi.org/10.3390/ ijms 17111682

Mirza, R., DiPietro, L.A. and Koh, T.J. (2009). Selective and Specific Macrophage Ablation Is Detrimental to Wound Healing in Mice. The American Journal of Pathology, 175(6), 2454-2462. https:// doi.org/10.2353/ajpath.2009.090248

Moreira, C., Cassini-Vieira, P., Silva, M. and Barcelos, L. (2015). Skin Wound Healing Model-Excisional Wounding and Assessment of Lesion Area. BIOPROTOCOL, 5(22), e1661. https://doi.org/10.21769/ BioProtoc. 1661

Musalmah, M., Nizrana, M.Y., Fairuz, A.H., NoorAini, A.H., Azian, A.L., Gapor, M.T. and Ngah, W.W. (2005). Comparative effects of palm vitamin $\mathrm{E}$ and $\alpha$ -tocopherol on healing and wound tissue antioxidant enzyme levels in diabetic rats. Lipids, 40(6), 575580. https://doi.org/10.1007/s11745-005-1418-9

Musalmah, M., Fairuz, A.H., Gapor, M.T. and Ngah, W.Z.W. (2002). Effect of vitamin $\mathrm{E}$ on plasma malondialdehyde, antioxidant enzyme levels and the rates of wound closures during wound healing in normal and diabetic rats. Asia Pacific Journal of Clinical Nutrition, 11(s7), S448-S451. https:// doi.org/10.1046/j.1440-6047.11.s.7.6.x

Nurden, A.T., Nurden, P., Sanchez, M., Andia, I. and Anitua, E. (2008). Platelets and wound healing. Frontiers in Bioscience: A Journal and Virtual Library, 13(9), 3532-3548. https:// doi.org/10.2741/2947

Ochoa, O., Torres, F.M. and Shireman, P.K. (2007). Chemokines and Diabetic Wound Healing. Vascular, 15(6), 350-355. https:// doi.org/10.2310/6670.2007.00056

Okizaki, S., Ito, Y., Hosono, K., Oba, K., Ohkubo, H., Amano, H., Shichiri, M. and Majima, M. (2015). Suppressed recruitment of alternatively activated macrophages reduces TGF- $\beta 1$ and impairs wound healing in streptozotocin-induced diabetic mice. Biomedicine and Pharmacotherapy, 70, 317-325. 
https://doi.org/10.1016/j.biopha.2014.10.020

Okonkwo, U.A., Chen, L., Ma, D., Haywood, V.A., Barakat, M., Urao, N. and DiPietro, L.A. (2020). Compromised angiogenesis and vascular Integrity in impaired diabetic wound healing. PLOS ONE, 15(4), $\mathrm{e} 0231962$.

https://doi.org/10.1371/

journal.pone. 0231962

Paswan, S.K., Srivastava, S. and Rao, C.V. (2020). Wound healing, antimicrobial and antioxidant efficacy of Amaranthus spinosus ethanolic extract on rats. Biocatalysis and Agricultural Biotechnology, 26, $101624 . \quad$ https://doi.org/10.1016/ j.bcab.2020.101624

Patel, S., Srivastava, S., Singh, M.R. and Singh, D. (2019). Mechanistic insight into diabetic wounds: Pathogenesis, molecular targets and treatment strategies to pace wound healing. Biomedicine and Pharmacotherapy, 112, $108615 . \quad \mathrm{https} / /$ doi.org/10.1016/j.biopha.2019.108615

Qing, L., Fu, J., Wu, P., Zhou, Z., Yu, F. and Tang, J. (2019). Metformin induces the M2 macrophage polarization to accelerate the wound healing via regulating AMPK/mTOR/NLRP3 inflammasome singling pathway. American Journal of Translational Research, 11(2), 655-668.

Ramasastry, S.S. (2005). Acute wounds. Clinics in Plastic Surgery, 32(2), 195-208. https:// doi.org/10.1016/j.cps.2004.12.001

Rasik, A.M. and Shukla, A. (2000). Antioxidant status in delayed healing type of wounds. International Journal of Experimental Pathology, 81(4), 257-263. https://doi.org/10.1046/j.1365-2613.2000.00158.x

Schürmann, C., Goren, I., Linke, A., Pfeilschifter, J. and Frank, S. (2014). Deregulated unfolded protein response in chronic wounds of diabetic ob/ob mice: A potential connection to inflammatory and angiogenic disorders in diabetes-impaired wound healing. Biochemical and Biophysical Research Communications, 446(1), 195-200. https:// doi.org/10.1016/j.bbrc.2014.02.085

Serbinova, E., Kagan, V., Han, D. and Packer, L. (1991). Free radical recycling and intramembrane mobility in the antioxidant properties of alpha-tocopherol and alpha-tocotrienol. Free Radical Biology and Medicine, 10(5), 263-275. https:// doi.org/10.1016/0891-5849(91)90033-Y

Siddiqui, S., Khan, M.R. and Siddiqui, W.A. (2010). Comparative hypoglycemic and nephroprotective effects of tocotrienol rich fraction (TRF) from palm oil and rice bran oil against hyperglycemia induced nephropathy in type 1 diabetic rats. ChemicoBiological Interactions, 188(3), 651-658. https:// doi.org/10.1016/j.cbi.2010.08.010
Stadelmann, W.K., Digenis, A.G. and Tobin, G.R. (1998). Physiology and healing dynamics of chronic cutaneous wounds. The American Journal of Surgery, 176(2, Supplement 1), 26S-38S. https:// doi.org/10.1016/S0002-9610(98)00183-4

Steed, D.L. (1997). The Role of Growth Factors in Wound Healing. Surgical Clinics, 77(3), 575-586. https://doi.org/10.1016/S0039-6109(05)70569-7

Tottoli, E.M., Dorati, R., Genta, I., Chiesa, E., Pisani, S. and Conti, B. (2020). Skin Wound Healing Process and New Emerging Technologies for Skin Wound Care and Regeneration. Pharmaceutics, 12(8), 735. https://doi.org/10.3390/pharmaceutics12080735

Wall, S.J., Bevan, D., Thomas, D.W., Harding, K.G., Edwards, D.R. and Murphy, G. (2002). Differential expression of matrix metalloproteinases during impaired wound healing of the diabetes mouse. Journal of Investigative Dermatology, 119(1), 9198. https://doi.org/10.1046/j.15231747.2002.01779.x

Wan Nazaimoon, W. and Khalid, B.A.K. (2002). Tocotrienols-rich diet decreases advanced glycosylation endproducts in non-diabetic rats and improves glycemic control in streptozotocin-induced diabetic rats. Malaysian Journal of Pathology, 24(2), 77-82.

Xu, C., Bentinger, M., Savu, O., Moshfegh, A., Sunkari, V., Dallner, G., Swiezewska, E., Catrina, S.-B., Brismar, K. and Tekle, M. (2017). Mono-epoxytocotrienol- $\alpha$ enhances wound healing in diabetic mice and stimulates in vitro angiogenesis and cell migration. Journal of Diabetes and Its Complications, 31(1), 4-12. https://doi.org/10.1016/ j.jdiacomp.2016.10.010

Xu, Z., Han, S., Gu, Z. and Wu, J. (2020). Advances and Impact of Antioxidant Hydrogel in Chronic Wound Healing. Advanced Healthcare Materials, 9(5), 1901502. https://doi.org/10.1002/adhm.201901502

Yu, J.-W., Deng, Y.-P., Han, X., Ren, G.-F., Cai, J. and Jiang, G.-J. (2016). Metformin improves the angiogenic functions of endothelial progenitor cells via activating AMPK/eNOS pathway in diabetic mice. Cardiovascular Diabetology, 15, 88. https:// doi.org/10.1186/s12933-016-0408-3

Zolali, E., Shayesteh, S., Rahbarghazi, R., Vaez, H., Heidari, H.R. and Garjani, A. (2020). Metformin Had Potential to Increase Endocan Levels in STZInduced Diabetic Mice. Pharmaceutical Sciences, 26 (2), 133-141. https://doi.org/10.34172/PS.2020.2 